e nsaio $_{\mathbf{n}}$

vol $5 \cdot n^{\circ} 2 \cdot$ out 2003

\title{
A AUTO-EXCLUSÃO DOS ALUNOS DAS ESCOLAS PÚBLICAS ESTADUAIS DE BELO HORIZONTE NO VESTIBULAR DA UFMG
}

\author{
Self-Exculsion in University Entrance Exam \\ Among Students from Public Schools in Belo Horizonte, B razil
}

José Francisco Soares*

Renato Júdice**

\begin{abstract}
Resumo
Esta nota tem como objetivo mostrar que a auto-exclusão é uma característica marcante para os alunos das escolas públicas estaduais de Belo Horizonte. Para tanto, foram utilizados os dados do Censo Escolar de 2001 e os registros do vestibular da Universidade Federal de Minas Gerais de 2002.
\end{abstract}

Palavras-chave: exclusão, ensino superior, vestibular

\begin{abstract}
The goal of this work is to show that self-exclusion is a characteristic of students from public schools in Belo Horizonte. We use data from 2001 School Census and 2002 records of the entrance exam from the Federal University of Minas Gerais.
\end{abstract}

Key-words: exclusion, college education, college entrance exam

\section{INTRODUÇÃO}

São comuns as discussões sobre as desigualdades de condições que os candidatos apresentam ao prestarem um concurso de vestibular. Segundo um "senso comum", um aluno de uma escola da rede particular tem maiores chances do que um aluno da rede estadual. Isto é entendido como se a escola pública fosse de pior qualidade. Na verdade, o que ocorre é uma imagem ligeiramente distorcida, tanto das escolas públicas quanto das particulares, no que se refere à influência que elas podem ter para mudar o desempenho cognitivo de seus alunos. De um modo geral, supõe-se que a influência das instituições públicas de ensino seja muito menor do que realmente ela é. Enquanto que, para as escolas particulares, supõe-se uma influência muito maior do que a real. Esta imagem distorcida

\footnotetext{
* Departamento de Estatística - UFMG

**GAME - UFMG
} 


\section{ensaio}

vol $5 \cdot n^{\circ} 2 \cdot$ out 2003

da realidade pode ser uma das causas do fenômeno que pretendemos analisar nesta nota - a auto-exclusão em massa dos alunos da rede estadual de Belo Horizonte no vestibular da UFMG. Isto porque o alunado não confiando na escola em que estuda, não chega nem a se inscrever no vestibular de uma universidade que também é pública.

Trabalhos como o de Soares et al (2001) mostram que algumas escolas públicas podem até não alcançar um grande número de aprovações nos vestibulares mais concorridos, mas, com certeza, elas modificam a realidade dos alunos que nelas estudam. São as chamadas escolas eficazes. E o que deve ser ressaltado é o fato de que elas chegam ao patamar de eficazes não por influência externa, tais como o nível socioeconômico e cultural de seus alunos ou a participação da família no processo de aprendizagem, mas por causa de políticas internas da própria escola. Ou seja, já está se fortificando no Brasil a linha de pesquisa que objetiva medir esse fator que pode ser denominado de "efeitoescola", corrigindo finalmente aquela imagem distorcida da influência escolar na aprendizagem do aluno. Essa linha de pesquisa, em momento algum, nega a grande influência de fatores externos, tais como o nível socioeconômico, na proficiência do aluno. Ela apenas almeja “dar a César o que é de César"... definindo melhor a participação de cada fator. E é justamente baseado nos resultados dessas pesquisas que afirmamos que os alunos da rede estadual não deveriam se auto excluir dessa maneira, já que as escolas deles não estão tão mal assim, e nem as escolas particulares estão tão boas como eles pensam.

No entanto, nesta nota estamos preocupados com outro enfoque, e não com as condições que os alunos chegam para prestarem o vestibular. Pretendemos sim, explicitar a autoexclusão como uma característica marcante das escolas estaduais de Belo Horizonte. Ou seja, iremos apresentar dados oficiais que mostram que grande parte dos alunos da rede estadual nem sequer se candidatam a uma vaga no vestibular da UFMG.

Para obter essa medida da auto-exclusão fizemos uma comparação entre o número de alunos matriculados no 3a ano do ensino médio na rede estadual em 2001, dados obtidos do Censo Escolar de 2001, e o número de alunos, dessas mesmas escolas, que se inscreveram no vestibular da UFMG em 2002.

\section{DADOS}

Primeiramente temos que explicitar um pouco mais sobre a medida que estamos fazendo da auto-exclusão. Na verdade, esta é apenas uma medida do número de alunos que nem mesmo chega a concorrer no vestibular, seja lá qual for o motivo. O nosso grupo de pesquisa é composto por todas as escolas públicas estaduais de Belo Horizonte que 


\section{ensaio}

vol $5 \cdot \mathrm{n}^{\circ} 2 \cdot$ out 2003

oferecem o ensino médio regular. Estas escolas, na sua grande maioria, são compostas por um alunado de baixo índice socioeconômico, ou como diria Bourdieu, de pequeno capital cultural (BOURDIEU, 1999). Evidentemente, não temos escolas rurais neste grupo. Porém, mesmo dentre essas escolas urbanas a diversidade de localização é grande, existindo desde escolas nas regiões centrais até aquelas de periferia.

O fato do vestibular da UFMG ser referência não só em Belo Horizonte, mas em toda Minas Gerais, já serviria como justificativa para sua escolha nesta pesquisa. No entanto, existe uma outra justificativa bem mais importante, que é o fato desta universidade ser pública, consequientemente com o ensino gratuito. E os candidatos podem até mesmo pleitear a isenção da taxa de inscrição para o vestibular. Vale lembrar aqui que, segundo depoimentos da atual reitora da universidade, a UFMG é a instituição federal de ensino que mais concede a isenção da taxa de inscrição no Brasil. Como o perfil socioeconômico dos estudantes das escolas estaduais de Belo Horizonte não condiz com o pagamento de mensalidades elevadas nas faculdades particulares, podemos concluir que, se existe uma instituição de ensino superior em Belo Horizonte adequada para os alunos da rede pública estadual, esta instituição é a UFMG.

Para efeito de cálculos, estamos supondo que a diferença entre o número de alunos matriculados no 3a ano do ensino médio no ano de 2001, o qual chamaremos a partir de agora de alunos matriculados, e o número de alunos inscritos no vestibular da UFMG em 2002 e que afirmaram ter terminado a educação básica em 2001, neste trabalho denominaremos esta variável de alunos inscritos, seja uma boa aproximação da auto-exclusão. Afirmamos ser essa uma boa aproximação porque nem todos os alunos que estavam matriculados no início de 2001 conseguiram concluir o ensino médio. Porém, é muito mais simples e eficaz trabalhar com esse dado oficial do Censo Escolar, sobre o número de alunos matriculados, que pode ser facilmente obtido no INEP, do que tentar um contato com cada uma das escolas estaduais de Belo Horizonte para obter uma informação sobre o número de formandos do 3o ano.

Outro fator relevante é que optamos por trabalhar com o número relativo da autoexclusão e não com o número absoluto. Fizemos isso porque caso seja necessária uma comparação entre as escolas dentro desse grupo, um número absoluto poderia levar à inferências errôneas.

Portanto, nossa medida foi obtida de aeordo eom a equaȩão abaixo: 
Ou seja, nossa medida da auto-exclusão é um número que varia entre 0 (zero) e 1 (um). Sendo que, quanto mais próximo de um, maior será o número de alunos que nem sequer se matricularam no vestibular da UFMG, logo maior o índice de auto-exclusão.

Existem 263 escolas estaduais em Belo Horizonte. No entanto, apenas 103 fornecem dados. As outras 160 são aquelas que não têm ensino médio, estão paralisadas ou até mesmo aquelas que, por algum motivo, não tiveram alunos matriculados no 30 ano em 2001.

\section{RESULTADOS}

Vários são os fatores que podem nos levar a análise que desejamos fazer. Apresentaremos a seguir um histograma com a distribuição de freqüências da variável auto-exclusão. A partir deste histograma chamaremos a atenção para fatores estatísticos relevantes, tais como o valor mínimo da auto-exclusão; o valor médio; a mediana; e uma divisão de frequiências por quartil. Ao realizar essa análise percebemos que algumas escolas merecem ser destacadas por apresentarem um índice de auto-exclusão menor que o restante do grupo. Isto também será feito, inclusive com um esforço de caracterização destas escolas. Infelizmente, essa análise estatística vai evidenciar um elevado índice de auto-exclusão, mesmo para aquelas escolas que foram destacadas do grupo.

\subsection{Histograma}

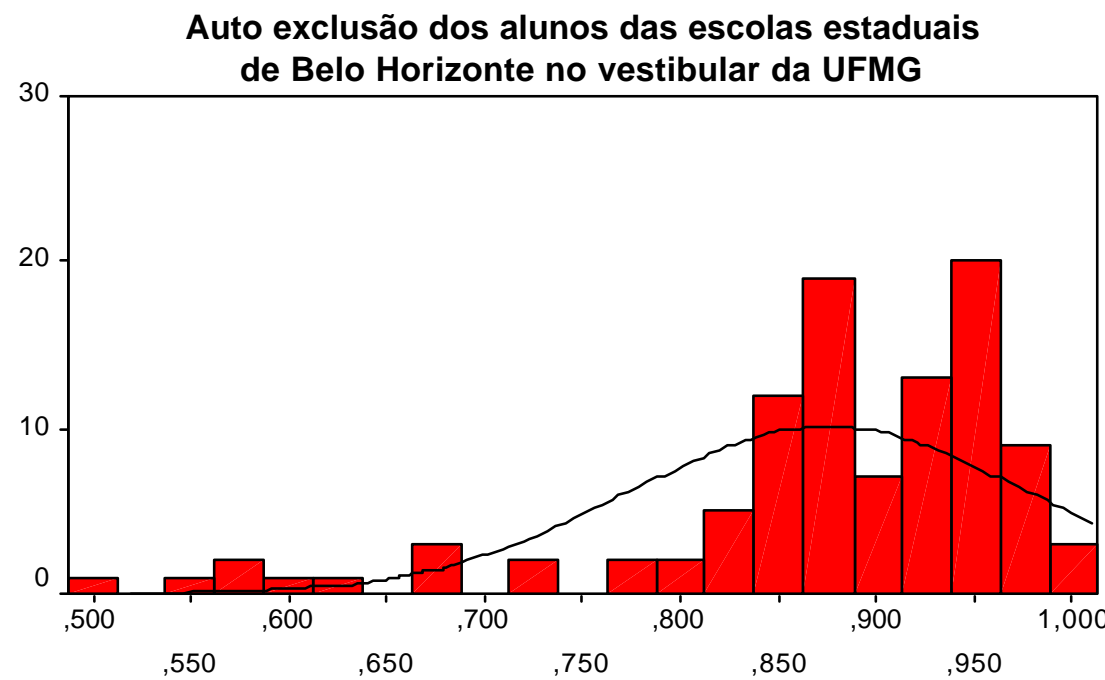

Medida da auto-exclusão 


\section{ensaio}

vol $5 \cdot n^{\circ} 2 \cdot$ out 2003

Este gráfico funciona como um ótimo recurso visual para confirmar o fato de que a grande maioria das escolas públicas estaduais de Belo Horizonte possui índice de auto-exclusão muito alto no vestibular da UFMG. Já que estão fortemente concentradas no lado direito do gráfico, próximo de 1,0 .

O valor mínimo da auto-exclusão é 0,502 . Ou seja, dentro de todo o grupo, na escola que tem o menor índice de auto-exclusão ele vale 0,502 . Isso quer dizer que, dos alunos que se formam no ensino médio desta escola, $50 \%$ nem sequer se matricularam no vestibular da UFMG. Com certeza, ainda um valor muito alto para aquela que é a escola que tem o maior índice de alunos se matriculando neste vestibular.

Além do valor mínimo, também são importantes os três valores a seguir:

$\begin{array}{llll}- & \text { Valor médio } & \Rightarrow & 0,87510 \\ - & \text { Desvio Padrão } & \Rightarrow & 0,10157 \\ \text { - } & \text { Mediana } & \Rightarrow & 0,88933\end{array}$

Refletindo sobre esses valores podemos fazer as seguintes inferências: como a média é muito alta e o desvio padrão é pequeno podemos concluir que a grande maioria das escolas tem um índice de auto-exclusão elevado. $O$ fato da mediana também ser muito alta só reforça essa inferência. Comparando os valores da média e da mediana (o segundo é ligeiramente maior que o primeiro) podemos afirmar que a curva de distribuição de freqüência para essa variável é ligeiramente inclinada para a esquerda. Ou seja, a maioria das escolas está concentrada no lado direito da curva, quer dizer, com índice próximo de 1.

Fazendo o cálculo de percentil e dividindo a distribuição de freqüências em quartil, obtemos os seguintes valores:

$\begin{array}{llll}- & \text { Quartil 25 } & \Rightarrow & 0,84599 \\ \text { - } & \text { Quartil 50 } & \Rightarrow & 0,88933 \\ - & \text { Quartil 75 } & \Rightarrow & 0,94686\end{array}$

Analisando esses valores podemos afirmar que em $75 \%$ das escolas estaduais de Belo Horizonte mais de $84 \%$ dos alunos nem se matriculam na UFMG.

Portanto, são vários os indícios de que a auto-exclusão dos alunos das escolas estaduais de Belo Horizonte no vestibular da UFMG é muito alta. 


\section{ensaio}

vol $5 \cdot n^{\circ} 2 \cdot$ out 2003

\subsection{Destaques e Caracterização}

Apesar dos índices de auto-exclusão serem muito altos, como visto anteriormente, ainda assim existem algumas escolas que se destacaram do grupo. Quer dizer, mesmo tendo um índice alto, o valor obtido por essas escolas é bem menor que o restante. Essas escolas são aquelas representadas no lado esquerdo do histograma mostrado na página 04 .

Esse fenômeno pode ser mais bem visualizado no "Box-plot" abaixo.

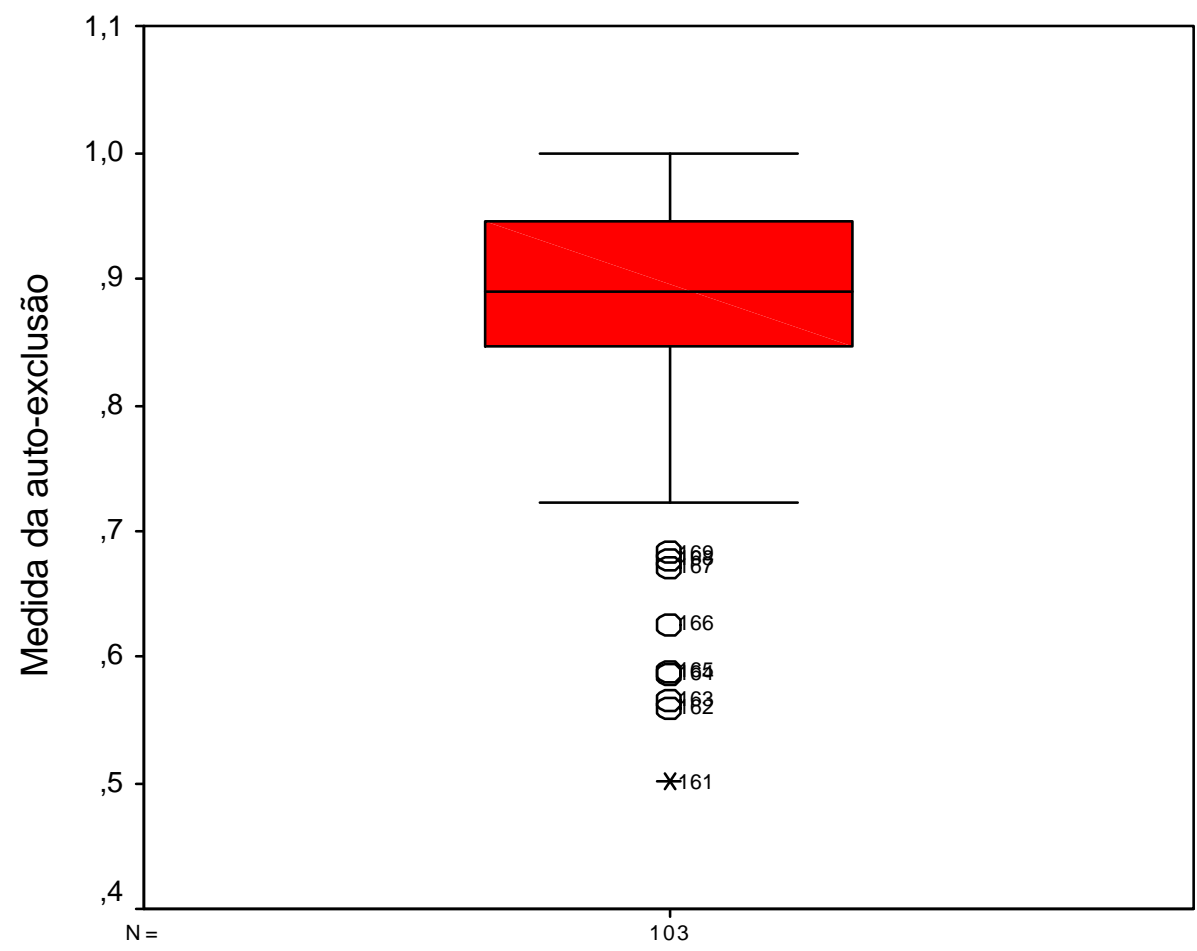

Neste gráfico fica explícito que algumas escolas destacam-se da média do grupo, que é próxima de 0,9 . Essas escolas, cujo índice de auto-exclusão não chega a atingir 0,7 , estão listadas na tabela da próxima página. Com um especial destaque para o Colégio Tiradentes da PMMG, o qual teve o menor índice de auto-exclusão de Belo Horizonte, 0,502. 
ensaio

vol $5 \cdot \mathrm{n}^{\circ} 2 \cdot$ out 2003

Ao analisar os dados da tabela, constatamos que apesar dessas escolas merecerem um destaque especial por possuírem os menores índices de auto-exclusão do grupo, ainda assim esses valores são altos, acima de $50 \%$. O que reforça a característica marcante da auto-exclusão nos alunos da rede estadual de Belo Horizonte em relação ao vestibular da UFMG.

Uma observação importante é que os dados a que tivemos acesso não nos permitiam diferenciar os 4 (quatro) colégios Tiradentes da capital. Portanto, somamos todos os dados, tanto de alunos matriculados como de alunos inscritos, e o resultado apresentado é como se houvesse um único colégio Tiradentes em Belo Horizonte.

Não é simples definir quais são as causas para o "baixo" índice de auto-exclusão no grupo de escolas estaduais destacado na tabela anterior. Muito pelo contrário, o modelo é complexo. No entanto, ficamos tranqüilos para afirmar que, certamente, essas escolas possuem algumas características em comum. Algumas características tais como: ambiente propício ao ensino; infra-estrutura adequada e em bom estado de conservação; existência e utilização de recursos materiais e pedagógicos; formação adequada e experiência dos professores e diretores; apoio da família aos alunos; e outras. Enfim, é um grande número de características que atuando de forma dinâmica e conjunta influenciam não só o desempenho do aluno, mas até mesmo a sua decisão de inscrever-se ou não em um concurso de vestibular. 


\section{DISCUSSÕES E CONCLUSÃO}

A primeira observação que fazemos refere-se ao nome empregado na grandeza que nos propusemos a medir: auto-exclusão. Alguns pesquisadores e setores da sociedade não aceitam esse nome para o que se propõem. Segundo eles, não são os alunos que se autoexcluem, mas, sim, fatores externos que os levam a desistir de sequer tentar uma vaga em um concurso de vestibular. Reconhecemos a relevância desse argumento, bem como, as dificuldades enfrentadas por esse conjunto de alunos durante sua trajetória de vida. No entanto, ainda assim, preferimos optar por manter o nome auto-exclusão, não só pelo consenso de utilização na literatura mas, também, por entendermos que não estamos, em momento algum, negando a causa dos fatos, somente explicitando-os.

Como já era esperado, a conclusão que chegamos ao término desta pesquisa é que a taxa de auto-exclusão dos alunos das escolas estaduais de Belo Horizonte é muito alta. $\mathrm{Ou}$ seja, agora que já está constatado que auto-exclusão é grande, deveríamos começar a refletir sobre o porque dela acontecer e tentar minimizá-la. Uma sugestão que se coloca é que, de alguma maneira, as políticas públicas para a educação do estado de Minas Gerais devem ser repensadas de tal forma que os alunos dessas escolas, pelo menos, comecem a concorrer naquele que é o mais importante vestibular do estado.

Outro ponto importante é nos lembrarmos que estamos vivendo as discussões sobre a possibilidade de criação de cotas nas instituições de ensino superior para alunos oriundos de escolas públicas. Independente de nos posicionarmos contra ou a favor dessas cotas, o fato é que o resultado desta nota deveria ser levado ao conhecimento daqueles que vão tomar a decisão neste caso. Afinal, uma disponibilidade maior de vagas com certeza mudaria o quadro da auto-exclusão.

E por fim, que os esclarecimentos desta nota sirvam como incentivo para minimizar as desigualdades de acesso e de qualidade da educação brasileira.

\section{REFERÊNCIAS BIBLIOGRÁFICAS}

SOARES, J. F., ALVES, M. T. G. \& OLIVEIRA, R. M. - O efeito de 248 escolas de nível médio no vestibular da UFMG nos anos de 1998, 1999 e 2000. Estudos em Avaliação Educacional. São Paulo: no 24, jul-dez: p. 69-117, 2001.

BOURDIEU, P. - Escritos de educação. $2^{\mathrm{a}}$ edição. Maria Alice Nogueira e Afrânio Catani (organizadores). Petrópolis. Editora Vozes. 1999. 